Mariano Latorre

\title{
Vaca indiana
}

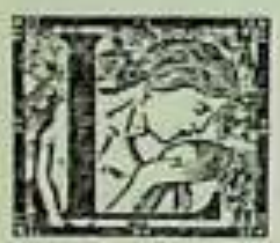

pastizal.

Los primeros sintomas del alumbramiento despertaban en la vaca negra-de aqui su campesino apodo de la Breva-una invencible angustia de andar: la deforme hinchazón de sus flancos le daba un aspecto monstruoso: del extremo de las ubres tiesas, de un rosa inflamado, caían goterones de leche que iban dejando un reguero blanquecino en la espesa verdura del trebolar.

Doscientos animales pacian en el gran potrero cerrado hacia el camino por una sólida cerca de palos a pique. enormes trozos de pellines y coigües que prolongaban hasta perderse en una quebrada boscosa su siméfrico alineamiento: más allá se espesaba la selva virgen como una cortina brumosa y oscura.

Se habia adelantado prematuramente el crudo invierno del sur en el mes de Mayo: el agua caía abundante desde varios dias. Aumentó el caudal de los esteros y la humedad ennegreció el paisaje con su caracteristica patina oscura. Desolado era el aspeclo de la campiña, porque al innumerable ejército de los palos quemados, de rotos brazos implorantes, se agregaba la fila de los pellines despojados de su rumoroso follaje de verano.

Al azote del viento caían los palos podridos, azotando la tierra con estruendo: muchas veces desplomábanse sobre cercas vicjas y los potreros quedaban abierlos. Las otras vacas. ya paridas, no se movian del potrero. pegadas al frébol jugoso que retonaba exhuberante después de las sequias estivales: pero la Breva. la única vaca que aún no habia parido, salió al campo y se perdió en el monte: en el quilantar enmarañado. lejos de la vida, esperó el momento supremo, arrodillada en la tierra húmeda, que cubria una roja alfombra de hojas secas barnizadas por el agua.

Desencadenábase de nuevo el norte aullador, que se colgaba de las copas hojosas de los coigües y remecia los recios pellines; en su ulular inacabable se 
ahogaba el murmullo de los chubascos y el bramar de la vaca que iba a ocultar del hombre y de las bestias de la selva, por un ancestral instinto de conservación. el producto de sus amores.

Sucio. viscoso, de largas patas endebles, el ternerillo yacia como muerfo sobre las hojas rojizas: la madre empezó a lamerlo con ternura: y su lengua áspera, semejante al modelador de un escultor, daba la forma de un ser a aquella masa informe como un montón de arcilla sanguinolenta: los párpados caidos se alzaban poco a poco y la luz blanca del dia nublado. mensaje de la vida exterior, encendia en ellos una chispita brillante; su pelaje negro se secaba y una vigorosa palpitación estremecia sus flácidos costados.

Al finalizar ese día, se hincó como para caminar. Su cabecita ciega buscaba el calor de la madre que se habia levantado; y seguia lamiendo sin cansarse al recental. El testuz del ternero golpeaba ahora entre los brazuelos y la vaca lo alentaba con un mugido suave, tibio. consolador: era una nota de cálida maternidad que prestaba un alma a aquel escondido rincón de la montaña. mojado por la lluvia, donde los troncos centenarios tenian una felpa de musgos y parásitos; el chucao de los charcos. entre el varillaje de las quilas, lanzaba de cuando en cuando su risotada plebeya y a intervalos un huio silvaba en el ramaje verde oscuro de los coigües.

La vaca, inmóvil. iluminadas sus grandes pupilas vidriosas por una ternura libia, miraba a aquel hociquillo torpe que tanteaba en sus costados buscando algo oscuro y profundo como el origen de la vida: habia en aquella mirada un magnético mandato y en aquel belfo húmedo una obediencia ciega, no más consciente que las ventosas de las enredaderas aferradas a los viejos pellines o a la fuga loca del estero hacia la paz de la laguna.

Mientras fanto, en el misterio tibio del vientre. las ubres hinchadas como globos goleaban el bálsamo de nieve de la leche, insinuando un camino al ávido hociquillo del recental.

La Breva era una vaca criolla, una de las últimas que aún quedaban en aquella hacienda donde se multiplicaba el lomo recto y la cabeza crespa del loro holandés: su disparejo contorno negro era alli, entre los ärboles, una excepción, su leche escasa, pero al decir del campero la más sabrosa por ser leche de vaca negra sus cuernos torcidos como la horquilla de un palo seco y las puntiagudas ancas denunciaban la raza vieja. cansada: pero fuerte, hecha a lodas las miserias de aquella tierra en formación: era una hermana de los altos robles musicales, de los perros lanudos como lobos y de los caballejos de ancas desiguales que llevan por los caminos rojos el cuerpo de bronce de los mapuches.

Ella lenia aún los resabios de la vida primitiva, medio salvaje de campo antiguo: ocultaba cuidadosamente su cría en un lugar seguro, al abrigo del puma y de los builres; sus compañeras. de cuernos cortos y abultadas carnes. parian en el establo tibio, ayudadas por el vaquero con la comodidad de obesas señoras respetables. 
El ternerillo seguia con su cabeza testaruda pegado al costado de la vaca. como si una misteriosa fuerza lo clavase alli; de cuando en cuando resbalaba algunos centímetros y se inmovilizaba de nuevo. La vaca, que rumeaba sus reservas de pasto. lo miraba entonces con sus grandes pupilas cansadas: y fué un minuto de vida cálida, un retazo de calurosa maternidad cuando el hociquillo insconciente encontró la ubre y todo su cuerpo succionó ávidamente la vida misma: su cabeza blanqueó con la espuma de la leche; la vaca lamialo nuevamente por el anca; y su macizo corpachón enflaquecido, huesudo. parecía estremecerse al dar generosamente a su hijo su albo tesoro, maravillosa transformación de las yerbas jugosas de la pradera.

Afuera habia un momento de calma. El bosque, empapado de agua, comenzaba a gotear: gruesos diamantes que se escurrian por los cuchillos de las quilas al menor movimiento de los flexibles colihues y se iban a perder en la áspera piel de los negros troncos.

Al dia siguiente la vaca caminó hacia el exterior: sentía un apremiante deseo de satisfacer su apetito: el ternerillo intentó algunos pasos con sus patitas endebles; pero no pudo: la vaca miró un momento hacia atrás y siguió su camino. Su ausencia no debía durar mucho; en el bosque también había peligros: los zorros ladrones están siempre sobre aviso en el corazón de la selva y sobre ella pasa el vuelo negro de los jotes.

La Breva experimentó al salir, un deslumbramiento: una inesperada claridad bañó sus ojos que se habían acostumbrado a la penumbra de las umbrias: su cuerpo enflaquecido se arqueaba a veces en contorciones dolorosas y por sus anchas narices se escapaba violentamente la respiración contenida; sobre las hojas de los robles. sobre los troncos atravesados en el camino. iba quedando un reguero de sangre viscosa, rastros de la anónima tragedia del alumbramiento.

Sus ojos inspeccionaban inquietos los menores movimientos de los matorrales; sus ódos recogian todos los ruidos insólifos con aguda percepción: no se alejó mucho, sin embargo. Ramoneó con ansia las hojuelas de las quilas, el alimento de sus antepasadas, no ignorando que más allá del estero. sus hermosas compañeras de potrero rumiaban calmadamente la abundancia del trébol oloroso: bajó al agua que hervia entre piedras y troncos caídos y bebió larga, ansiosamente.

Un prolongado, sonoro bramido del toro la estremeció: su cabeza coronada por la tosca cornamenta se alzó destilando agua iquiên sabe qué gérmenes de recuerdos se cruzaron por sus redondas pupilas brillantes en ese momentol

La oscura nota de su cuerpo, en el blanco dia ofoñal, se destacaba crudamente. como el montón de los palos quemados en medio del potrero. como los troncos de los coigües entre cuyas astillas podridas suele brotar el verde ramillete del renuevo. 
No llovia, pero amenazantes escuadrones de nubes parecian nacer tras de la selva y marchar. sobre los campos, hacia la cordillera invisible.

La Breva giró. de pronto, su cabeza ágilmente. Un perro flaco. la cola enIre las piernas, se escurría hacia el bosque; un rojo destello de cólera inflamó la mansedumbre de sus ojos: embistió al animal que se perdió rápido entre los macales.

La vaca desanduvo, entonces, el camino y volvió donde su cria: su llegada la marcó un concierto de chucaos y de huios entre las ramas; una gallareta contestó con una estridente carcajada invisible.

El recental siguió. esta vez, un trecho a la vaca con un trolecillo torpe.

Violentamente la tempestad se desencadenaba: aún no llovía, pero el viento norle azotaba de nuevo los altos robles y los desnudos esqueletos de los árboles secos: silbaba entre las quilas y lo envolvia todo en un estruendo sordo: a veces se oía crujir de astillas y el golpe seco de un árbol desplomado: luego las ráfagas se enredaban sibilantes entre las ramas desnudas o en los coigües. las hojas tiesas de otoño chocaban con un murmullo de marejada.

La vieja vaca, conocedora de los peligros de la selva, levantaba inquieta su cabeza a cada uno de estos ruidos. El ternerillo bebia golosamente, dando ahora cabezazos como para precipitar hacia su boca insaciable todo aquel espumante chorro de leche. La vaca limitábase a volver su cabeza sin moverse.

En ese momento se produjo la catástrofe; ni el más leve sonido la hizo presentir: la música lenta de la lluvia recogía lodos los ruidos vagos del campo en su persistencia monocorde. El gigantesco coigüe, viejo rey de la vieja selva. se desplomó pesadamente: los duros gajos en que terminaba su tronco envolvieron a la Breva en un abrazo mortal: la lengua viscosa resbaló por entre los belfos amoratados en un gesto de horroroso sufrimiento: en el aire persistió, un segundo. crujir de fibras desgarradas y revuelo de pájaros sorprendidos: y nada más.

La lluvia lenta. indecisa como una bruma. volvió a hacer oir su suave y monólono murmullo.

El ternerillo. indemne, no soltó la ubre: parecia más bien, contento por este aflujo de leche que le llegaba de improviso.

Ese mismo día. en un momento de calma, el patrón se acercó al rancho del campero, montado en su yegua alazana.

- ¿Le ha echado un vistazo en I'hacienda. on Venegas?

El campero, un viejo seco y harapiento, se apresuró a responder:

-Di albita, no más los campié, patrón.-Falta la Breva, la vaca indiana que pasó el estero por la cerca rofa.

- ¿Estaba preñada. no?

- Debe haber parido de juro y como es vaca indiana habrá escondido la crie: por ei estará enmontă. 
El hombre subió a su pingo, atado a un pilar del corredorcillo de la misera puebla: y patrón e inquilino atravesaron el potrero. Las vacas de raza fina, rojas y overas, pacian tranquilas en el trebolar; los terneros triscaban no muy lejos: el grueso toro los miró un segundo con sus ojos espesos por la grasa y hundió. luego, su cabeza en el pasto.

Cortaron Tácilmente el rastro de la Breva: sus pezuñas estaban estampadas en el fango de la margen y continuaban hacia el monte en la ofra orilla.

Debieron dejar maneados los caballos, pues el coigüe interceptaba el sendero con la macicez de su enorme tronco. El patrón observó esa seguridad dogmática del campesino:

- Al fin el norle voltió el palo. Las raices taban en el agua.

El campero miró el coigüe un segundo con piedad cariñosa; aquel palo lo vió nacer: alli se deluvo una vez un enjambre que luego encerrô en una caja: su hacha lo respetó siempre con un temor supersticioso.

Se deslizaron a lo largo del tronco, acribillado a trechos por el pico de los carpinteros: como una enorme lacra, invisible desde abajo, se mostraba el hueco donde vivió la colmena silvestre.

El campero iba delante: al llegar al enredo del ramaje saltó al otro lado: alli entre las quilas aplastadas y los arbustos rotos, vió la mancha negra de la vaca. la cabeza forcida, un cuerno desprendido de su alvéolo semejante a un gancho desgajado.

- Patrón, el coigüe pilló a la Breva, anunció el inquilino.

El patrón saltó a su vez; miró indiferente el cuerpo del animal: dijo luego con cierto temblor en la voz:

- ¿La pillaria antes de la parición?

- Pa mi que nó. El golpe lo senlí esta mañana: y la vaea salió antiayer. Puaqui ha de estar el guacho. no más.

Volvió a saltar el campero en sentido contrario: no tardó mucho en encontrarlo: bajo las quilas estaba el ternerillo negro, a dos pasos de las ubres que mostraban. en su hinchada convexidad, los cuatro pezones ereclos.

-Aquístá, patrón, avisó, al mismo tiempo que, con su cuchillo, corlaba quilas y boquis para despejar aquel enredijo vegetal que el coigüe formó en su caida.

La pregunta de reglamento voló como una flecha sobre el cadáver de la Breva. ávido. ansioso era el tono de la voz.

- Es ternera?

- Ternera es.

La voz del propietario se dulcificó de improviso.

-Esta raza indiana no se puede acabar. Venegas, dijo salisfecho, como si una vez más la suerte, esa deidad veleidosa de la campiña, lo hubiera favorecido.

Por la cabeza tosea del campero no pasaban, sin embargo, ideas alegres. Aquella vaca desmedrada era casi de él: de su leche vivian en el invierno los seis chiquillos siempre hambrientos: se hacian. en la primavera, quesillos sabrosos que asaban en las brasas: el patrón no le cederia, no, una vaca de raza fina: el rico era 
cicatero: la hija de la Breva estaba lejos y resultaria una buena lechera, porque tenia sangre del toro fino.

Su voz ruda denunció una amarga tristeza que pasó inadvertida para el patrón. al decir, casi bromeando:

- Taria e Dios que muriera la vaca indiana: por eso salió el guacho e luto. Breva.

Una sonrisa ensanchó la cara roja del patrón: y cste lué el epitafio de la 